\title{
An Investigation into Vibration in Switched Reluctance Motors
}

\author{
by \\ P.Pillay, W.Cai \\ ECE Dept., Clarkson University, Box 5720, Potsdam, NY 13699 \\ Phone: 315-268-6509, Fax: 315-268-7600 \\ email: pillayp@sun.soe.clarkson.edu
}

\begin{abstract}
:
Two disadvantages of the SRM are its torque ripple and acoustic noise. Previous work on vibration modes and resonant frequencies of the laminations of an 8-6 SRM is extended here to include the effects of the frame. Both a smooth frame and a ribbed frame are examined and the presence of numerous additional vibratory modes in the ribbed frame demonstrated. Accelerometer tests behind a pole verify some of the theoretical predictions.
\end{abstract}

\section{INTRODUCTION}

Switched reluctance motor drives are making their presence felt in a variety of applications from power steering to washing machines to traction. This inroad into the marketplace is based on their advantages over the induction motor in manufacturing, reliability and robustness.

Two disadvantages of the machine are its torque ripple and acoustic noise. Some previous work has been done in this area, but the research is far from exhausted. The origin of the acoustic noise in SRMs can be broadly classified into two types: mechanical and magnetic. Some of the sources interact with each other and increase the vibration and noise emission. The inverter and the control strategies can affect both mechanical and magnetic noise. The acoustic noise sources are listed as follows:

1) Bearing vibration, due to its construction and any installation errors, causes acoustic noise, which is of pure mechanical origin;

2) SRMs have a doubly salient structure. The rotor poles behave like blades, which cause acoustic noise due to windage;

3) Non-uniform characteristics of materials produce mechanically dynamic unbalance of the rotor and a non-uniform distribution of magnetic flux, which cause both magnetic and mechanical forces on the rotor and results in acoustic noise;

4) Manufacturing asymmetries of the rotor and stator, especially a non-uniform air gap, excites asymmetric forces on the rotor;

5) Stator windings, that are not installed well or manufactured well, can move actively or passively when the motor is running;

6) The currents through the stator windings interact with local magnetic fields to produce forces on the windings, which can excite windings vibration;

7) The laminations of both stator and rotor in SRMs experience magneto-restrictive forces. The forces can cause lamination vibration of the stator and rotor, with the problem being aggravated if stator is not well stacked;

8) The torque ripples produced by many common control strategies are considerably larger in SRMs than those in many other motors. The torque ripple, in fact, is the tangential magnetic force exerted on the poles. They mainly excite stator vibrations;

9) The commutation of the tangential forces, which are exerted on the poles of the stator and the rotor and produce torque, can excite the vibration of the stator and rotor;

10) There exists a strong concentrated radial magnetic attraction between stator and rotor poles, especially in the SRM with doubly salient structures. This attractive force leads to stator vibrations.

Some of the above sources of acoustic noise in SRMs have been presented by many authors $[1,2]$ and examined in some depth by calculation or experiment [2-6]. It is almost widely accepted that the radial attraction force between stator and rotor is the dominant source of the vibration and acoustic noise in SRMs with doubly salient structures. However the torque shifts among poles may not be omitted [7].

The existing research on acoustic noise can be mainly divided into two categories-frequency domain methods [8-11] and time domain methods $[3,6,12]$. The frequency domain method is useful to show the spectrum and dominant components of the noise and vibrations. In addition, it can be used to predict the resonant frequencies in terms of the geometry of the motor. The time domain method can reveal the links between acoustic noise, stator 
vibration, shape and timing of the applied voltage and the current in the phase winding of the motor. To understand the effects of the power electronic converter on acoustic noise, the time domain is particularly useful.

In order to identify which factors affect the production of vibration and acoustic noise, experiments have been performed on existing SRMs of different designs [1-6]. The odd current harmonics, which coincide with the natural stator frequencies, excite the vibration modes more easily than even current harmonics coinciding with the natural resonant frequencies [2,12]. The pure mechanical noise (bearing, windage and unbalance etc.) in some motors is not significant. If the commutation of the phase current happens at or near the aligned position between stator and rotor axes, the acoustic noise is the most prominent. The torque ripple does excite some noise but at a reduced level than the radial forces.

It has been shown that the structure and construction materials of the motor influence the nature of the stator vibration [3]. The magnitude of the radial force is a function of the phase current and rotor position. The current flowing through the phase windings depends on parameters such as phase number, lamination shape, resistance and inductance of the windings etc. which are eventually fixed in the SRM and on variable parameters of the controller such as the supply voltage, turn-on and off angles, current chopping condition etc. The vibration induced behind a stator pole at 90 mechanical degrees to the excited pole is exactly 180 degrees out of phase with the vibration of the excited pole. The analysis and calculation of the magnetic forces and the dynamic response of the motor structure to these forces can be performed with the aid of a computer. This is examined in the following sections.

\section{VIBRATION ANALYSIS}

Usually, the main stages of the analysis and calculation are:

1) Component natural frequency calculation and verification: all of the mechanical components (stacked stator lamination, rotor, end shield etc.) of the motor, contribute to the acoustic noise and vibration, and are required to be modeled. The natural frequency and mode shapes of the components such as stator and rotor can be built either from a closed-form solution of analytical equations [8 11,13] or from finite element analysis. Because of the complexity of some components and non-linear coupling between component structures, the calculated model needs to be verified empirically [5]. The COSMOS/M or ANSYS is capable of predicting the mode shapes and the corresponding natural frequencies of the three dimensional physical model of the components. The damping factor can be obtained with "impact tests"[5].

2) Calculation and verification of the system natural frequency: after stage 1) is finished, the subassemblies (wounding stator, rotor stack with shaft etc.) model can be built and the natural frequencies and mode shapes calculated. Finally, the entire motor is assembled, physically and in the FE model whose accuracy should be verified by test data.

3) Electromagnetic model and force calculation: all the related dimensions, phase winding turns and the properties of all materials are installed in a software package, for instance, ANSYS, ANSOFT, MAGNET etc. to calculate the flux linkage curves as a function of rotor position and phase current. Usually the two-dimensional electromagnetic finite element model is applied, perhaps with a correctional factor for the three dimensional end effects. According to the flux linkage curves and the other parameters of the SRM as well as the operating parameters of the inverter controller, the current curves simulating the actual operation of the SRM can be obtained. Based on the current and rotor position, both radial and tangential forces are calculated. The vibration and acoustic noise are determined based on the results of the finite element analysis. Of course, the time trace of the phase current from the measurement can also be applied as excitation in the finite element model to calculate the electromagnetic forces of the motor.

4) System dynamic response calculation and verification: the calculated electromagnetic forces from the electromagnetic finite element analysis are applied to the mechanical model so that the dynamic vibration response in the physical system can be calculated with the mechanical finite element analysis. In the numerical analysis, the natural frequencies are obtained from the three FE calculations in step 1 , and the damping coefficients of the components found by impact test. It should be noticed that the dynamic analysis could be performed on any individual component, but only the response of the complete motor model 
should be obtained for both the actual noise testing and accelerometer measurements on the motor. Steps 1 and 2 are addressed in this paper, with $3 \& 4$ left for future research.

\section{III.VIBRATION MODES OF LAMINATIONS, SMOOTH FRAME AND RIBBED FRAME}

The vibration modes and resonant frequencies calculated with the aid of an ANSYS finite element package are given here for an 8-6 machine in figures 3.1(a)-(i). Some of the modes are easily exited by normal operation, while others would be difficult to excite. The resonant frequencies calculated from a structural finite element analysis are listed in Table 3.1. The normal forces excite the modes in figures 3.1(a), (d) and (e). The production of torque in the machine can excite modes 3.1(c) and 3.1(i). The other modes are excited by unsymmetrical excitation of the stator stack and are not considered here, although they may be excited during faulted conditions.

Though the radial electromagnetic forces are exerted on the stator teeth and poles, their vibration amplitude is much smaller than the amplitude of vibration of the stator yoke. An analytical method is developed here for the calculation of the resonant frequencies which concentrates on the natural vibration modes of the stator yoke. The following assumptions are made in predicting the frequencies: (1) the stator yoke is a round rigid body; (2) the teeth and windings have no rigidity, so that their mass is attached to the yoke; (3) the periodic force waves with $r$ th order are symmetrically exerted on the stator yoke ring; (4) the only effects of all defects and notches is a reduction in the mass.

The following formulas are used to predict the natural vibration frequencies for the force wave with $\boldsymbol{r}$ th order,

where $m$ is the equivalent mass per square meter $\left(\mathrm{kg} / \mathrm{m}^{2}\right)$ on the cylindrical surface at the average

$$
f_{r}=\frac{1}{2 \pi} \sqrt{\frac{k_{r}}{m}}
$$

yoke radius, which can be expressed by the following formula:

$$
m=\frac{M_{y}}{2 \pi R_{y(a v)} L_{y(e f f)}}
$$

and the equivalent spring stiffness coefficient per square meter $k_{r}\left(\mathrm{~N} / \mathrm{m}^{3}\right)$ on the cylindrical surface at average yoke radius can be written as $[15,16,17]$

$M_{y}$ is the yoke mass including stator windings and

$$
k_{r}= \begin{cases}\frac{E h_{y}}{R_{y(a v)}^{2}} & \text { for } \mathrm{r}=0 \\ k_{D} & \text { for } \mathrm{r}=1 \\ \frac{r^{2}\left(r^{2}-1\right)^{2}}{r^{2}+1} \frac{E h_{y}^{3}}{12 R_{y(a v)}^{4}} & \text { for } \mathrm{r} \geq 2\end{cases}
$$

poles $(\mathrm{kg}) ; h_{y}$ is the yoke height in the radial direction (m); $R_{y(a v)}$ is the average radius of yoke $(\mathrm{m}) ; L_{y(e f f)}$ is the effective length of yoke (m, $\left.L_{y(\text { eff })}=0.95 \sim 0.98 L_{y}\right) ; \quad k_{D}$ is the spring stiffness coefficient of the shock absorber under the $\operatorname{motor}\left(k_{D}=0\right.$ without absorber); $E$ is the elasticity modulus $\left(\mathrm{N} / \mathrm{m}^{2}, 1.177 \times 10^{11} \mathrm{~N} / \mathrm{m}^{2}\right.$ for lamination core); $r$ is the order of electromagnetic force waves.

The dimensions of a $4 \mathrm{~kW}$ (5.5hp) SRM are given as follows: $R_{s i}=4.818 \times 10^{-2}(\mathrm{~m}), R_{y}=7.84 \times 10^{-2}$ $(\mathrm{m}), \mathrm{R}_{\mathrm{so}}=8.98 \times 10^{-2}(\mathrm{~m})$, the pole arc of stator $\beta s=20.2^{\circ}$, pole number $\mathrm{N}_{\mathrm{s}} / \mathrm{N}_{\mathrm{r}}=8 / 6$, length of stator laminations $\mathrm{L}_{\mathrm{y}}=0.151(\mathrm{~m})$, the mass density of stator laminations $\rho_{\mathrm{Fe}}=7800\left(\mathrm{~kg} / \mathrm{m}^{3}\right)$, Young's elasticity modulus $\mathrm{E}=2.07 \times 10^{11} \mathrm{~N} / \mathrm{m}^{2}$, winding area $\mathrm{A}_{\mathrm{w}}=7 \times 24 \times 10^{-6}\left(\mathrm{~m}^{2}\right)$, turns of windings $\mathrm{N}=56$ turns/pole, specific mass of windings $\rho_{c}$ $=8.9 \times 10^{3}\left(\mathrm{~kg} / \mathrm{m}^{3}\right)$.

According to the above parameters, several natural vibration frequencies are obtained (shown in Table 3.1). Compared with the results using the finite element method, the natural vibration frequencies using the analytical formula $[15,16]$ has sufficient accuracy at the first 4 orders of the force waves. But several vibration modes and frequencies are missing between orders. In fact, these formulas are valid only under the limitation of $r h_{y}<<R_{y(a v) \text {. }}$

For example the analytical model is unable to predict mode $\mathrm{c}$ which the FE model predicts. This is because of the simplifying assumptions in the development of the analytical model. 


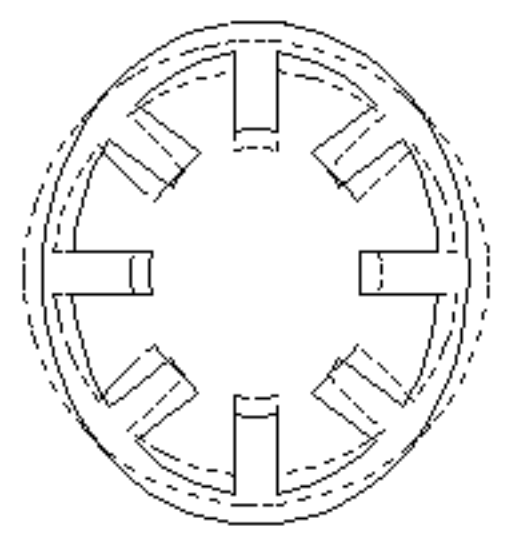

(a) Mode at $823 \mathrm{~Hz}$

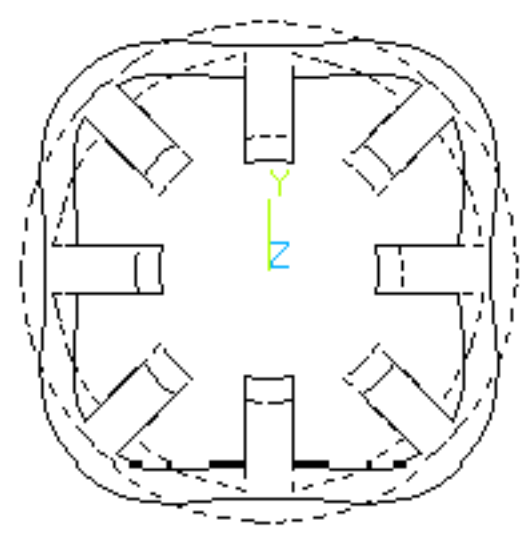

(d) Mode at $4533 \mathrm{~Hz}$

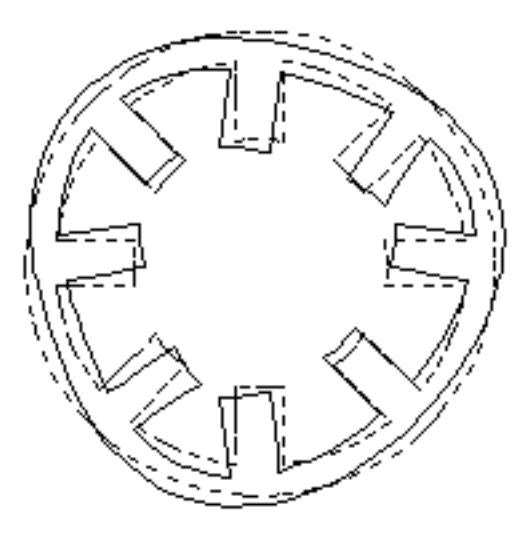

(b) Mode at $2132 \mathrm{~Hz}$

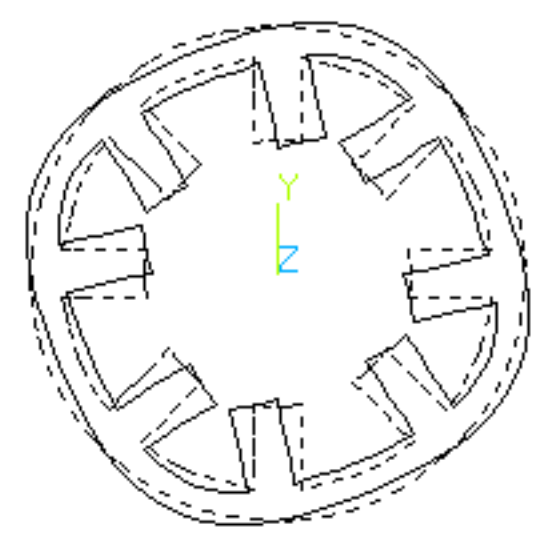

(c) Mode at $3242 \mathrm{~Hz}$

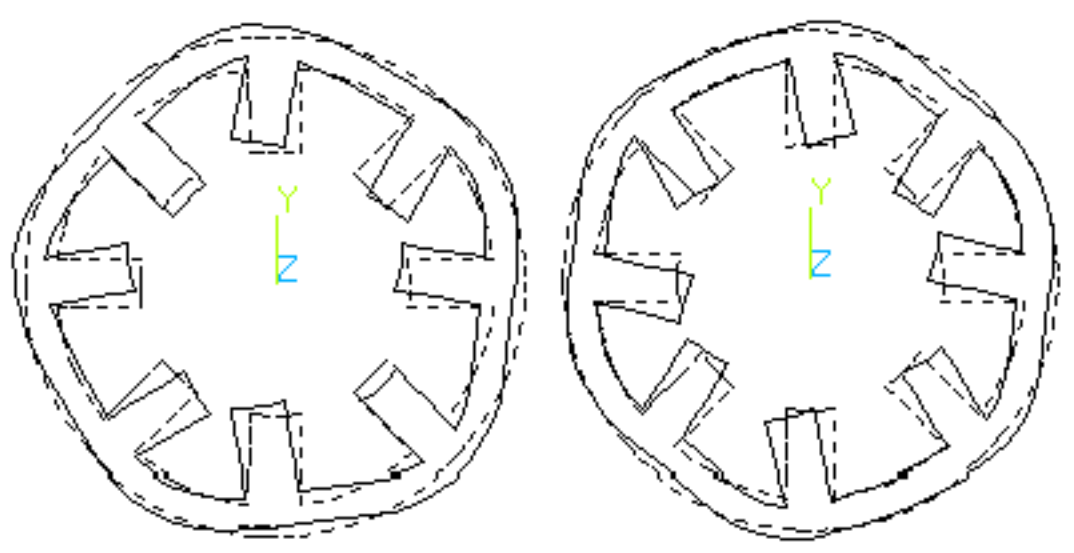

(e) Mode at $5600 \mathrm{~Hz}$

(f) Mode at $6762 \mathrm{~Hz}$

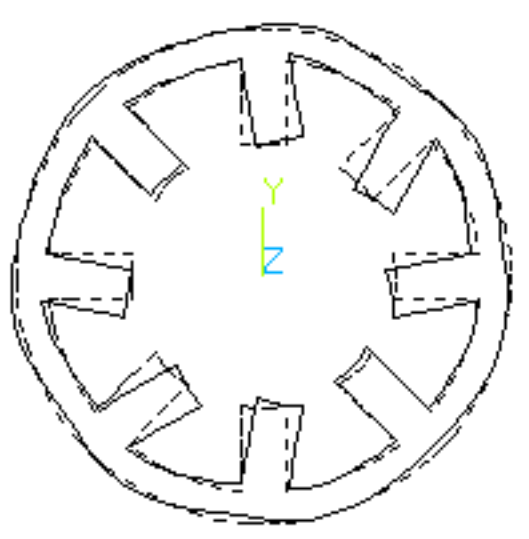

(g) Mode at $7433 \mathrm{~Hz}$

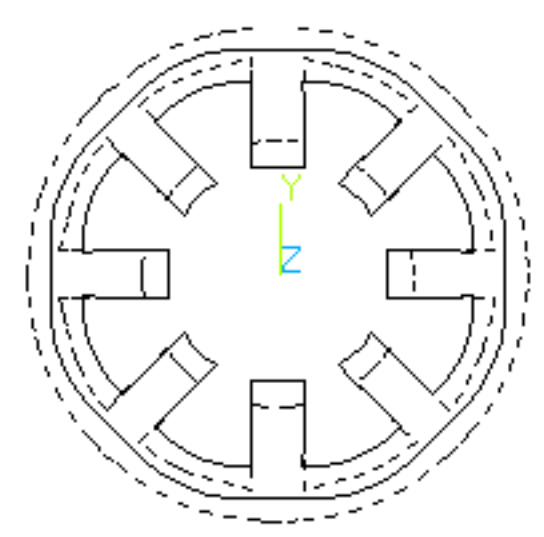

(h) Mode at $7577 \mathrm{~Hz}$

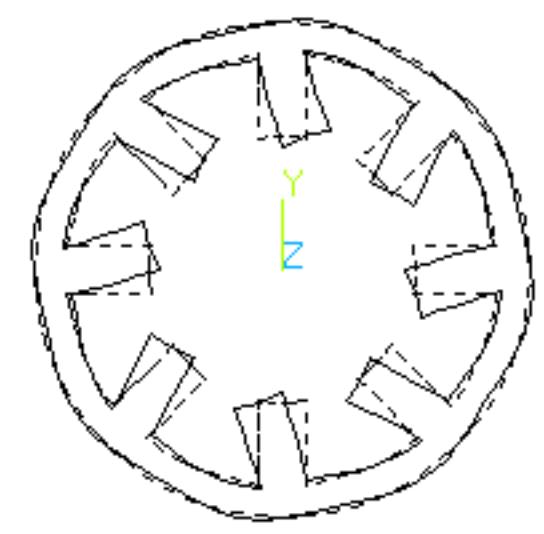

(i) Mode at $8149 \mathrm{~Hz}$

Fig. 3.1 Vibration Modes of the Stator Laminations of SRM 
Table 3.1 Modal Frequency Comparison

\begin{tabular}{|c|c|c|c|c|c|c|c|}
\hline \multirow{2}{*}{$\frac{0}{8}$} & \multicolumn{3}{|c|}{$\begin{array}{l}\text { Laminations } \\
\text { Stack }\end{array}$} & \multicolumn{2}{|c|}{$\begin{array}{l}\text { Smooth } \\
\text { Frame }\end{array}$} & \multicolumn{2}{|c|}{$\begin{array}{l}\text { Ribbed } \\
\text { Frame }\end{array}$} \\
\hline & $\begin{array}{l}\mathrm{FE} \\
(\mathrm{Hz})\end{array}$ & $\begin{array}{l}\mathrm{AN} \\
(\mathrm{Hz})\end{array}$ & $\%$ & $(\mathrm{~Hz})$ & $\%$ & $(\mathrm{~Hz})$ & $\%$ \\
\hline $\mathrm{a}$ & 823 & 788 & -4 & 1421 & 73 & $\begin{array}{l}1301 \\
1374 *\end{array}$ & $\begin{array}{l}58 \\
67 *\end{array}$ \\
\hline b & 2132 & 2228 & 5 & 3630 & 70 & $\begin{array}{l}3372 * \\
3568\end{array}$ & $\begin{array}{l}58 * \\
67 \\
\end{array}$ \\
\hline c & 3242 & N/A & & 5427 & 74 & 5136 & 58 \\
\hline d & 4533 & 4272 & -6 & 7255 & 60 & 6427 & 42 \\
\hline $\mathrm{e}$ & 5600 & 6908 & 23 & 8511 & 52 & 7261 & 30 \\
\hline $\begin{array}{l}\mathrm{f}, \\
\mathrm{ff}\end{array}$ & 6762 & N/A & & 9420 & & 9421 & \\
\hline $\mathrm{g}$ & 7433 & N/A & & 9624 & 29 & 9701 & 31 \\
\hline $\mathrm{h}$ & 7577 & N/A & & 7831 & 3 & 6707 & -11 \\
\hline $\mathrm{i}$ & 8149 & N/A & & 10003 & 23 & 10184 & 25 \\
\hline
\end{tabular}

Note: AN is based on the analytical formula

This paper also considers the effects of the frame on the mode shapes and frequencies. A tight friction coupling between the laminations and frame is assumed. Fig 3.2 shows the effects of adding a smooth frame to the stator laminations. The thickness of the frame corresponds to that of a commercial machine for the modes given in fig. 3.3(a)-(i). The first observation is that while several of the mode shapes that exist with the lamination only, also exist with the lamination and frame, there is a reordering of the mode shapes in terms of frequency. While the first 4 mode shapes of the laminations are also the first four in the lamination and frame, for example the mode shape at $7577 \mathrm{~Hz}$ labeled $\mathrm{h}$ in fig. 3.1 is shifted to the $5^{\text {th }}$ mode shape in terms of frequency for the case of the lamination plus frame. The figures in fig. 3.2 are presented in order of the increasing frequency yet labeled according to the base case in fig. 3.1. Thus fig. 3.1 (e) which is a mode at $5600 \mathrm{~Hz}$ is shifted to $8511 \mathrm{~Hz}$ in fig. 3.2 and is the $6^{\text {th }}$ highest mode and not the $5^{\text {th }}$ as shown in fig. 3.1(e). Mode $(f)$ in fig 3.1 has no correspondence in fig. 3.2 and similarly for mode (ff) in fig. 3.2. Where the mode shapes do coincide, there is a large increase in the frequency. For example, mode (a) occurs at $1421 \mathrm{~Hz}$ for the frame and lamination and at $823 \mathrm{~Hz}$ for the lamination alone, which is an increase of $73 \%$. These frequencies of the smooth frame and laminations are presented in Table 3.1 along with the corresponding increase in frequency for that particular mode.

Commercial machines often use ribs for improved cooling. Figure 3.3 shows the mode shapes and resonant frequencies when a ribbed frame is used. The particular mode shapes that are selected for fig 3.3 correspond to the same mode shapes of figure 3.2. The fins allow additional degrees of freedom in the motion of the frame/stack combination, thus creating the additional mode shapes. Two such cases are given in fig. 3.4 which are mode shapes that occur between modes (a) and (b) in fig. 3.3. Some modes, that are coincident in the lamination and lamination with smooth frame, become separated in the ribbed design because the ribs are not symmetrical around the periphery. For example, the $1^{\text {st }}$ mode of the lamination and lamination plus frame are split into 2 separate modes for the case of the ribbed frame. This is given in figs. 3.3(a) and (a'). Similarly mode (b) of fig. 3.2 are separated into (b) and ( $\left.b^{\prime}\right)$ for the case of a ribbed frame. These asymmetries are caused by the mounting feet, terminal block and lifting hook, which are not modeled in the lamination stack or lamination stack with smooth frame. The corresponding frequencies and percentage changes with respect to the base case of a lamination only is give in Table 3.1.

Given the influence of the frame on the natural frequency, it is therefore of interest to examine the effects of the frame thickness on the natural frequencies. Figure 3.5 summarizes the results for the case of a $\mathrm{z}$-constrained vibration of a smooth frame, showing a gradual increase in the frequencies of the mode shapes selected for analysis.

In practical machines, the frame length is often longer than the stack length to allow space for the end windings and possibly encoders. An analysis of the effects of increasing the frame length for a constant stack length of $151 \mathrm{~mm}$ is given in fig. 3.6. Initially, there is a slight increase in the modal frequency up to $190 \mathrm{~mm}$, but subsequently, there is a decrease in the modal frequency.

\section{Experimental Validation}

The experimental validation of vibration results is a non-trivial task, requiring the use of accelerometers, screwed into the motor frame, preferable behind a pole for maximum sensitivity. This was done on a practical $5.5 \mathrm{hp}$ commercial machine, with a single phase pulsed by a voltage waveform given in fig 3.7. The resulting triangular current and accelerometer output are given as well as the power spectral density of the accelerometer output. The frequency of resonance that is excited is $1340 \mathrm{~Hz}$, which corresponds closely to the predicted modal frequency of $1364 \mathrm{~Hz}$ given in figure 3.9. Similarly, the motor running at $575 \mathrm{rpm}$ 


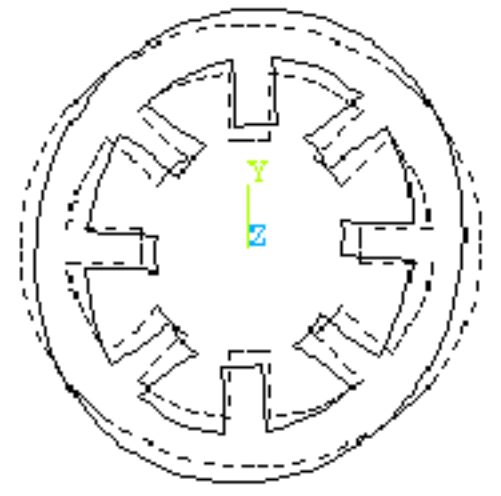

(a) Mode at $1421 \mathrm{~Hz}$

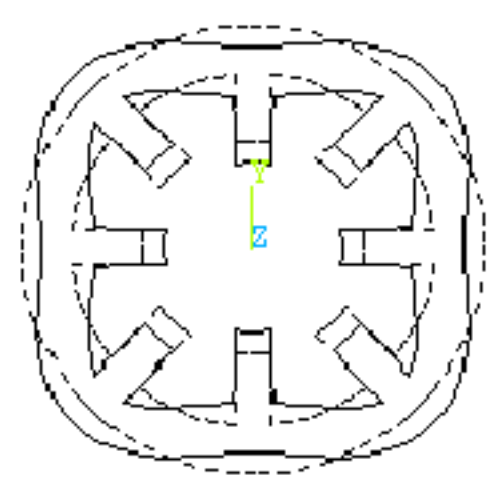

(d) Mode at $7255 \mathrm{~Hz}$

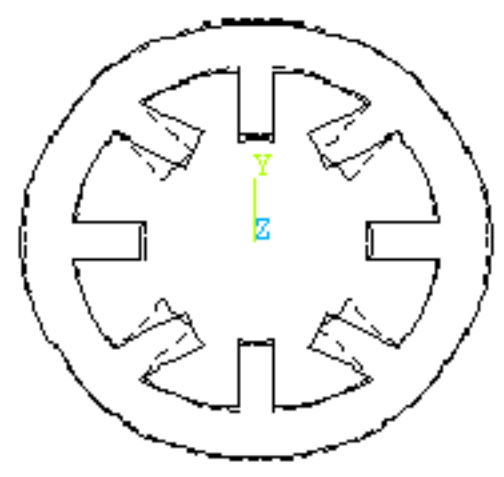

(ff) Mode at $9420 \mathrm{~Hz}$

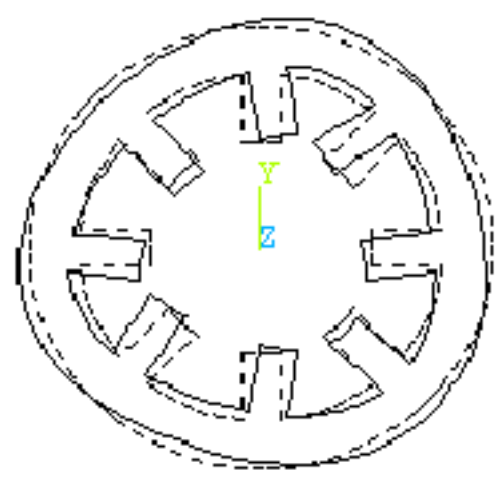

(b) Mode at $3630 \mathrm{~Hz}$

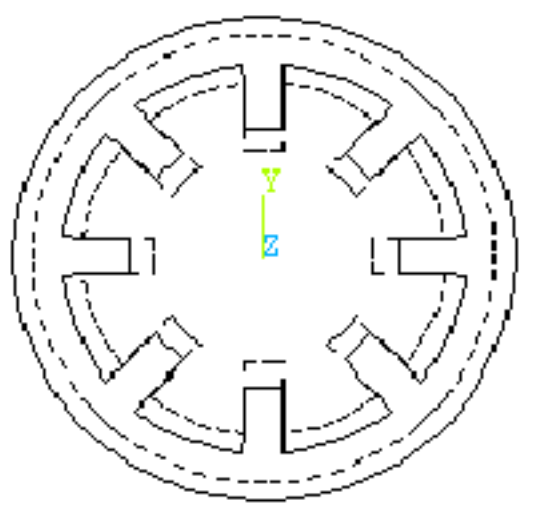

(h) Mode at $7831 \mathrm{~Hz}$

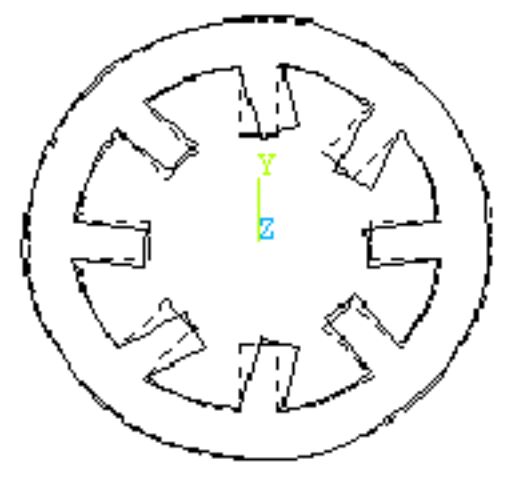

(g) Mode at $9624 \mathrm{~Hz}$

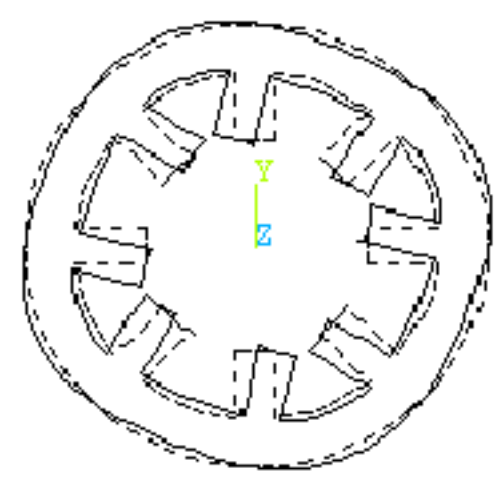

(c) Mode at $5427 \mathrm{~Hz}$

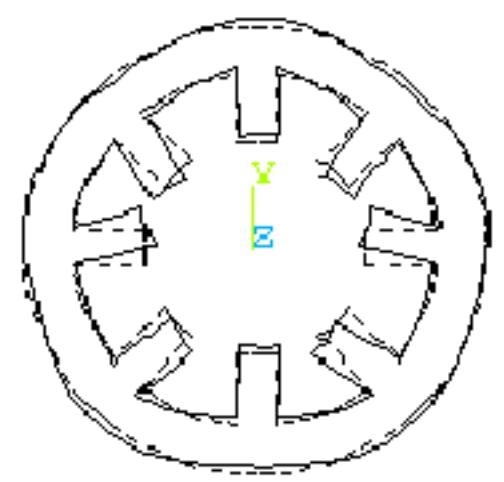

(e) Mode at $8511 \mathrm{~Hz}$

Fig. 3.2 Vibration Modes of the Stator Laminations \& Smooth Frame of SRM 


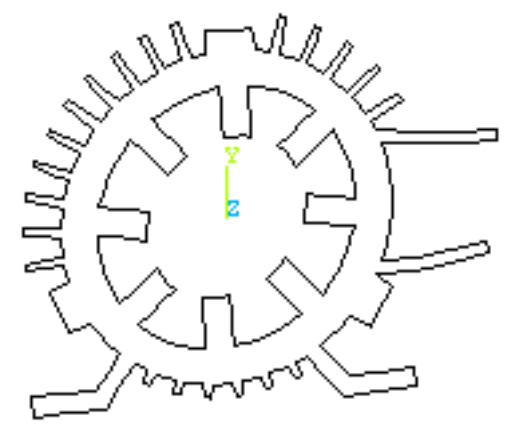

(a) Mode at $1301 \mathrm{~Hz}$

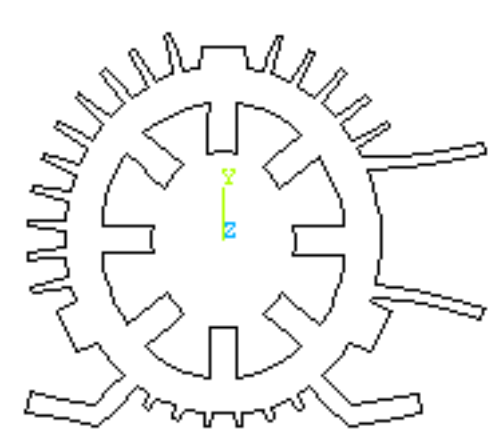

(a') Mode at $1374 \mathrm{~Hz}$

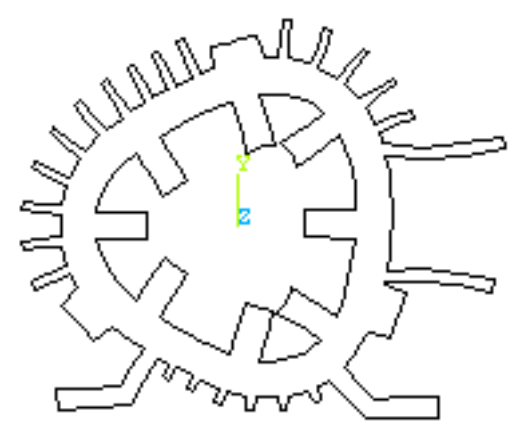

(b) Mode at $3372 \mathrm{~Hz}$

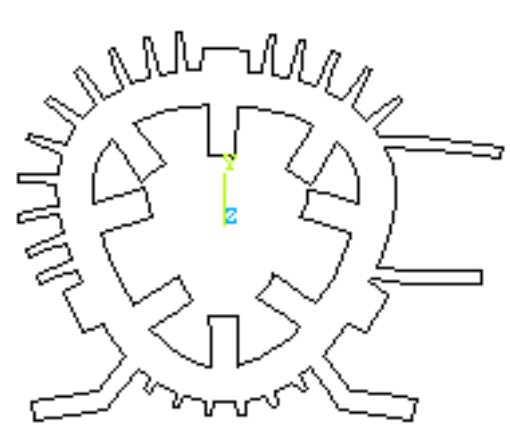

(b') Mode at $3568 \mathrm{~Hz}$

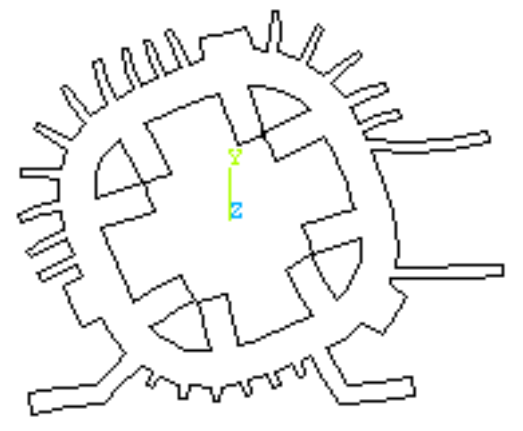

(c) Mode at $5136 \mathrm{~Hz}$

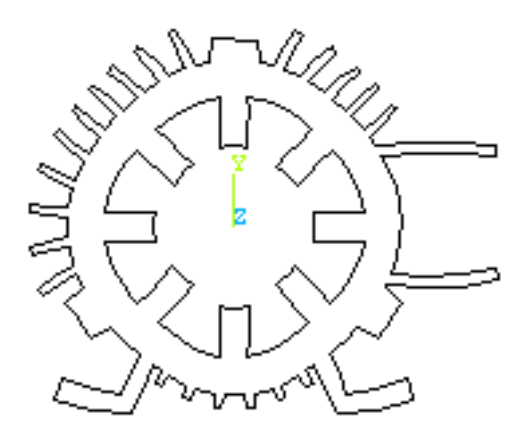

(d) Mode at $6427 \mathrm{~Hz}$

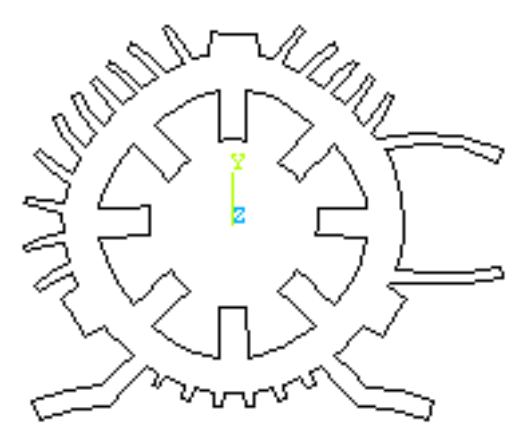

(h) Mode at $6707 \mathrm{~Hz}$

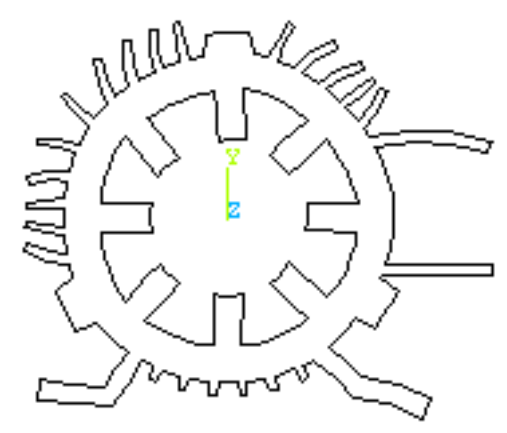

(e) Mode at $7261 \mathrm{~Hz}$

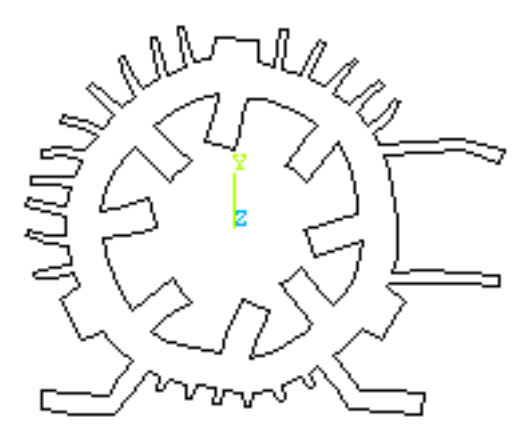

(ff)Mode at $9421 \mathrm{~Hz}$

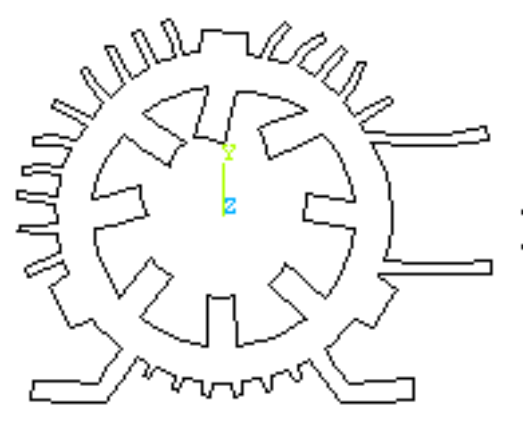

(g) Mode at $9701 \mathrm{~Hz}$

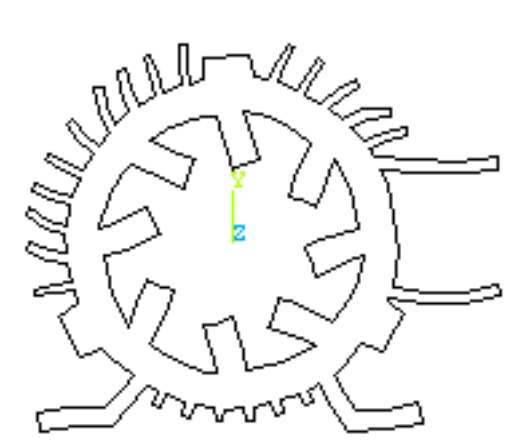

(i) Mode at $10184 \mathrm{~Hz}$

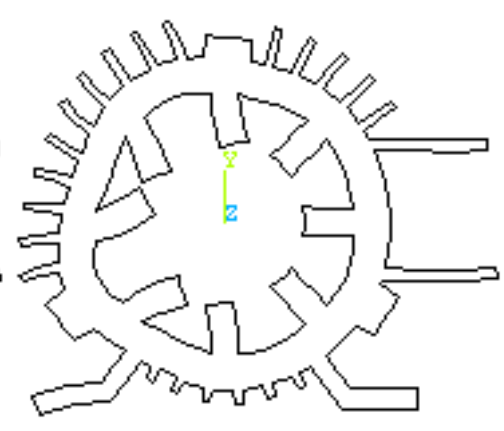

(j) Mode at $15009 \mathrm{~Hz}$

Fig. 3.3 Vibration Modes of the Stator Laminations \& Frame with Ribs 
also excites this mechanical mode; in addition a vibration corresponding to the fundamental frequency is also evident.

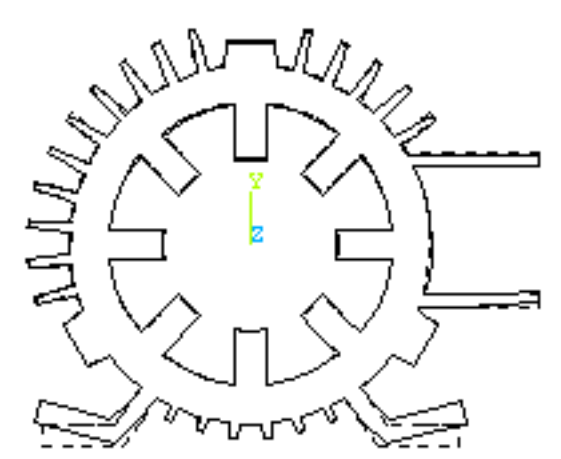

(a) Mode shape at $1640 \mathrm{~Hz}$

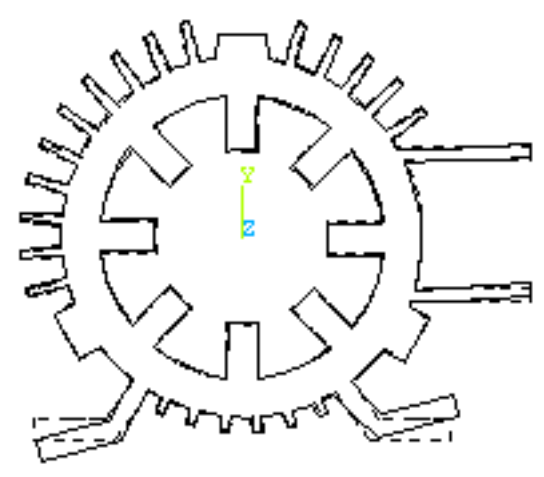

(b) Mode shape at $1756 \mathrm{~Hz}$

Fig. 3.4 Mode shapes between $2^{\text {nd }}$ and $3^{\text {rd }}$ modes

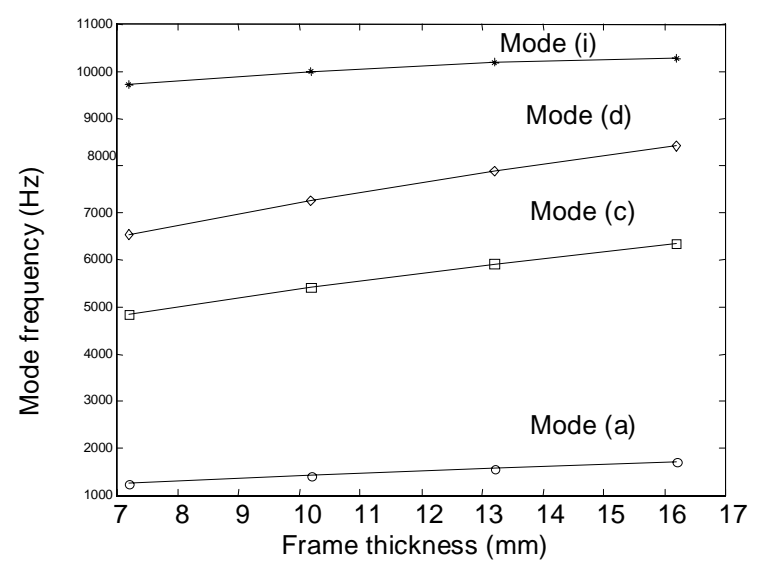

Fig. 3.5 Natural frequency vs. frame thickness

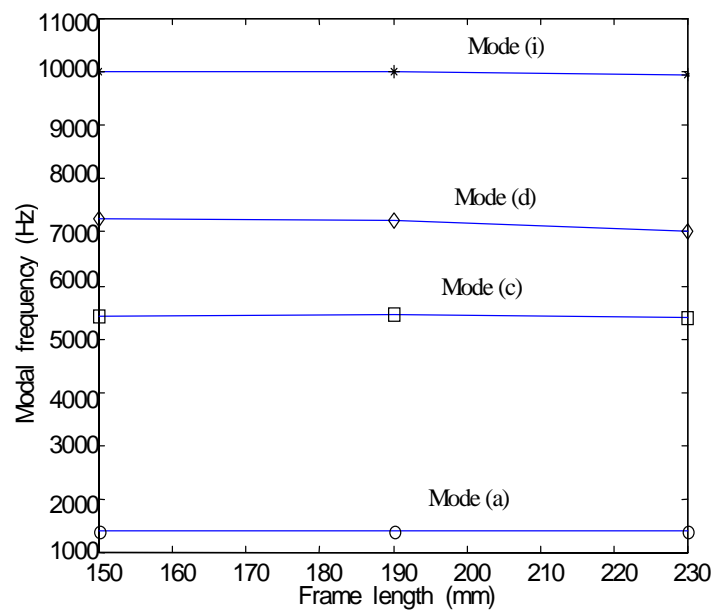

Fig. 3.6 Mode frequency vs. frame length when lamination stack is fixed at $151 \mathrm{~mm}$
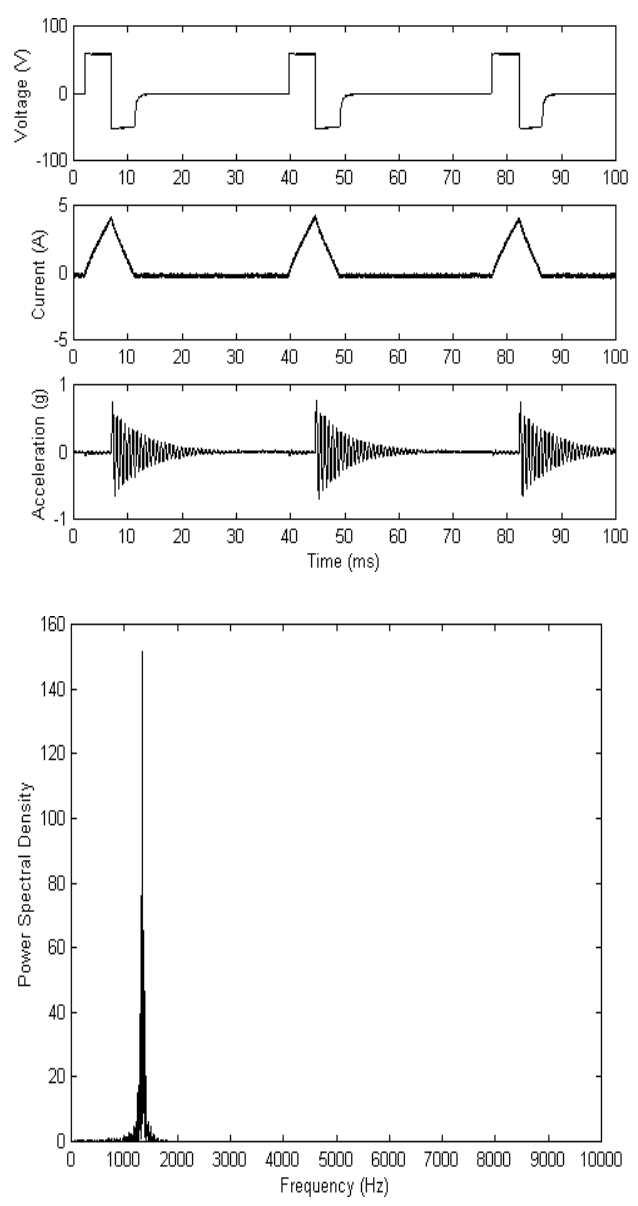

Fig.3.7 Frequency spectrum under single phase excitation $($ Repetition $=26.67 \mathrm{~Hz})$

Vibration dominant frequency $=1340 \mathrm{~Hz}$ 

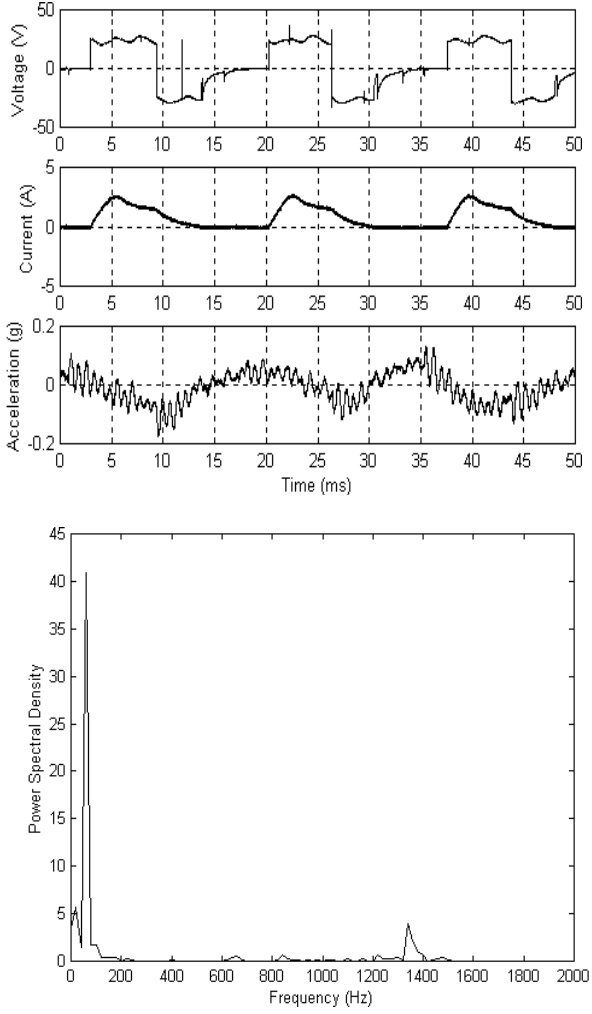

Fig. 3.8 Frequency spectrum under 4-phase excitation ( repetition $=5 * 3.5 \mathrm{~ms}$ )

Dominant frequency $\mathrm{f}=60 \mathrm{~Hz}, \mathrm{f}=1360 \mathrm{~Hz}$
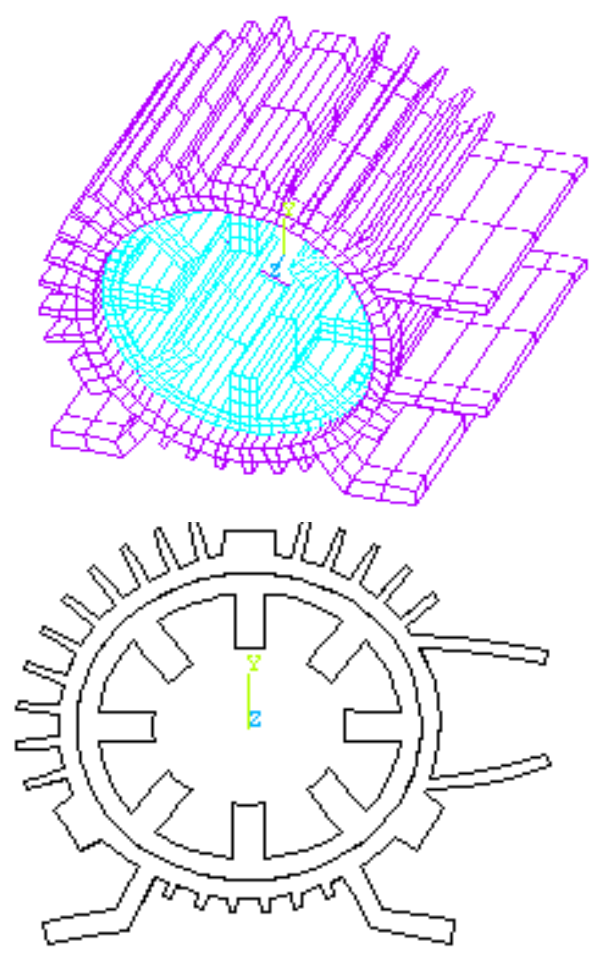

Fig 3.9 Mode shape at $1364 \mathrm{~Hz}$ for the machine

\section{CONCLUSION}

This paper has conducted an in-depth study of vibration modes of the stator of switched reluctance machines. The study started with the laminations, and was then extended to a smooth frame as well as a ribbed frame. The first few modes of the laminations were also predicted using an analytical formula with the disadvantage that simplifying assumptions necessary to make the problem tractable can lead to an inability in predicting certain modes. While the first few mode shapes remain the same, as one goes from the lamination to the smooth frame, there is a large increase in the corresponding frequency. There is also a change in the order of the mode shapes. The addition of ribs; feet and the termination block to the frame introduces numerous additional vibrating modes. Modes that are coincident in the symmetrical cases of the lamination or lamination with smooth frame become separated in the unsymmetrical machine.

The effects of changing the thickness and length of the frame were also examined, with length having less of an effect than thickness.

The results on a practical $5.5 \mathrm{hp} \mathrm{SRM} \mathrm{of} \mathrm{ribbed}$ frame design confirm some of the predictions with reasonable accuracy.

\section{ACKNOWLEDGEMENTS}

The authors acknowledge N. Boules for technical support, GM Corporate Research for financial support, Y. Liu for help with the measurements, G. Ahmadi for help with the analytical work and R. D. Pillay for helping with the preparation of the paper.

\section{References}

[1] R.S.Colby, F.Mottier, T.J.E.Miller, "Vibration modes and acoustic noise in a 4-phase switched reluctance motor", Conference Record of the 1995 IEEE Industrial Application Society, 30 ${ }^{\text {th }}$ IAS Annual Meeting, Vol.1, Orlando, USA, Oct. 8-12, 1995, pp.441 447.

[2] D.E. Cameron, J.H. Lang, S.D.Umans, "The origin and reduction of acoustic noise in doubly salient variable-reluctance motors", IEEE Trans. on Industry Applications, Vol.28, No.6, November/December, 1992, pp.1250 1255.

[3] Yifan Tang, "Characterization, numerical analysis and design switched reluctance motor for improved material productivity and reduced 
noise", Conference Record of the 1996 IEEE Industry Application Society, 31st IAS Annual Meeting, Vol.1, San Diego, USA, Oct. 6-10, 1996, pp.715 722.

[4] A.Michaelides, C.Pollock, "Reduction of noise and vibration in switched reluctance motors: new aspects", Conference Record of the 1996 IEEE Industrial Application Society, 31st IAS Annual Meeting, Vol.1, San Diego, USA, Oct. 6-10, 1996, pp.771 778.

[5] J.Mahn, Don Williams, P.Wung, G.Horst, J.Lloyd, S.Randall, "A systematic approach toward studying noise and vibration in switched reluctance machines: preliminary results", Conference Record of the 1996 IEEE Industrial Application Society, 31st IAS Annual Meeting, Vol.1, San Diego, USA, Oct. 6-10, 1996. pp.779

[6] C.Y.Wu, C. Pollock, "Time domain analysis of vibration and acoustic noise in the switched reluctance drive", IEE Sixth International Conference on Electrical Machines and Drives, London, UK, 1993, pp.558 563.

[7] W.Cai, J.Li, "Several Methods and design considerations to reduce the vibration and noise of switched reluctance motors", 1990's Research Reports of HIET, Harbin China, December, 1990, pp. 166 178 ( in Chinese).

[8] R.S.Girgis, S.P.Verma, "Experimental verification of resonant frequencies and vibration behavior of stators of electrical machines, part I-models, experimental procedure an apparatus", Proceedings of IEE, Part B, Vol.128, No.1, January 1981, pp.12 21.

[9] S.P.Verma, R.S.Girgis, "Experimental verification of resonant frequencies and vibration behavior of stators of electrical machines, part II-experimental investigations and results", Proceedings of IEE, Part B, Vol.128, No.1, January 1981, pp.22 32.
[10] S.P.Verma, R.S.Girgis, "Resonance frequencies of electrical machines stator having encased construction, part I: derivation of the general frequency equation", IEEE Trans. On Power Apparatus and Systems, Vol. PAS-92, No.5, September/October 1973, pp. 1577 1585.

[11] S.P.Verma, R.S.Girgis, "Resonance frequencies of electrical machines stator having encased construction, part II: numerical results and experimental verification", IEEE Trans. on Power Apparatus and Systems, Vol. PAS-92, No.5, September/October 1973, pp.1586 1593.

[12] C.Y.Wu, C.Pollock, "Analysis and reduction of acoustic noise and vibration in the switched reluctance drive", IEEE Trans. on Industry Applications, Vol.31, No.1, January/February, 1995, pp.91 98.

[13] S.P.Verma, R.S.Girgis, "Method for accurate determination resonant frequencies and vibration behavior of stators of electrical machines", Proceedings of IEE, Part B, Vol.128, No.1, January 1981, pp.1-11.

[14] P.Pillay, R.M.Samudio, M.Ahmed, P.T.Patel, "A Chopper-controlled SRM drive for reduced acoustic noise and improved ride-through capability using supercapacitor", IEEE Trans. on Industry Applications, Vol.31, No.5, September/October, 1995, pp.1029 1038.

[15] Shikun Chen, Electrical Machinery Design (edition 1), Press of Machinery Industry, Beijing, China, 1982 (in Chinese).

[16] Robert D. Blevins, Formulas for natural Frequency and Mode Shape, Van Nostrand Reinhold, New York, ISBN 0-442-20710-7, 1979, pp. 205.

[17] Warren C. Young, Roark's Formulas for Stress $\&$ Strain (sixth edition), McGraw-Hill, ISBN 007-072541-1, 1989, pp.67, 263. 